Historic, Archive Document

Do not assume content reflects current scientific knowledge, policies, or practices. 



\section{New Scarlet Geranium "HELEN MICHELL"}

We take pleasure in introducing to our many customers for 1913 THE NEW BRIGHT SCARLET GERANIUM

"Helen Michell"

This sterling novelty will be Disseminated jointly by the Henry F. Michell Co. and Richard Vincent, Jr. \& Sons Co.

Seedling Cross Jean Viand and Alphonse Ricart. Our claim for "Helen Michell" is that it Surpasses all Scarlet Geraniums

(1) In brilliancy of color.

(2) In size of bloom.

(3) In number of clusters to the individual plant.

(4) In vigor and strength.

(5) In earliness of bloom.

(6) In constancy of bloom.

(7) In propagating quality.

(8) In a wonderful ability to retain its brilliancy of color in the hottest of weather.

"HELEN MICHELL" IS SEMI-DOUBLE, OF THE CLEAREST POSSIBLE SHADE OF SCARLET, IS EARLY IN BLOOM, AND FLOWERS VERY FREELY DURING THE ENTIRE SEASON . .

It grows compact medium dwarf, with lustrous green foliage and throws up gigantic flower-heads very freely. We claim it to have the largest flower-heads of any of the Bedding Geraniums. The individual blooms measure $21 / 2$-inches across. It is a common occurrence that a single 4 -inch pot plant shows four fully open gigantic flower-spikes, several half open and more in bud.

Orders are filled in Rotation as booked, so please order now to get them early.

TO BE DISSEMINATED JANUARY-MARCH, 1913
FROM 21/4-INCH POTS.
PRICES TO THE TRADE:

Each, 25c. $\quad \$ 2.50$ Dozen. $\quad 100, \$ 15.00 . \quad 1000, \$ 125.00$ 
